\title{
Exploring Frontal Lobe Dysfunction in Schizophrenia with Positron Emission Tomography
}

\author{
Donald P. Hall, Jr., M.D.
}

National Institutes of Health, Bethesda, Maryland

Follow this and additional works at: https://jdc.jefferson.edu/jeffjpsychiatry

Part of the Psychiatry Commons

Let us know how access to this document benefits you

\section{Recommended Citation}

Hall, Jr., M.D., Donald P. (1990) "Exploring Frontal Lobe Dysfunction in Schizophrenia with Positron Emission Tomography," Jefferson Journal of Psychiatry. Vol. 8 : Iss. 1 , Article 11.

DOI: https://doi.org/10.29046/JJP.008.1.006

Available at: https://jdc.jefferson.edu/jeffjpsychiatry/vol8/iss1/11

This Article is brought to you for free and open access by the Jefferson Digital Commons. The Jefferson Digital Commons is a service of Thomas Jefferson University's Center for Teaching and Learning (CTL). The Commons is a showcase for Jefferson books and journals, peer-reviewed scholarly publications, unique historical collections from the University archives, and teaching tools. The Jefferson Digital Commons allows researchers and interested readers anywhere in the world to learn about and keep up to date with Jefferson scholarship. This article has been accepted for inclusion in Jefferson Journal of Psychiatry by an authorized administrator of the Jefferson Digital Commons. For more information, please contact: JeffersonDigitalCommons@jefferson.edu. 


\title{
Exploring Frontal Lobe Dysfunction in Schizophrenia with Positron Emission Tomography
}

\author{
Donald P. Hall, Jr., M.D.
}

Frontal lobe dysfunction in schizophrenic patients has been highly suspected for many years. Many psychiatrists and patients, however, are awaiting solid proof of a biological manifestation of this disease. While positron emission tomography does not uniformly demonstrate such a manifestation, it does demonstrate a prefrontal cortex deficit in most reported studies. Further, a localization of the attention deficit of schizophrenia, in the prefrontal cortex, is strongly suggested by some studies.

\section{INTRODUCTION}

Positron emission tomography (PET) has enabled investigators in modern clinical psychiatry to demonstrate that schizophrenia is, at least in part, a frontal lobe disorder. PET studies of many patients with schizophrenia exhibit a decreased level of metabolism in the frontal cortex. Other brain areas have also been investigated for their role in schizophrenia. These regions include the hippocampus (1), basal ganglia, limbic system, and other brainstem areas (2). This review, however, is limited to the deficit most consistently reported with PET brain metabolism studies-hypofrontality.

Frontal lobe dysfunction in schizophrenia has been suggested for many years by several research paradigms. Post-mortem studies have reported abnormal neurotransmitter receptor levels including serotonergic $(3,4)$, muscarinic (5), GABAergic (6), and others. Histological abnormalities in the frontal cortex of schizophrenic patients, including decreased cortical cells (neurons $>$ glia) in layer VI (7) and ultrastructural (EM) abnormalities in neurons (8), have been reported. Frontal lobe pathology has also been suggested by MRI studies, reporting significantly smaller frontal lobes in schizophrenics (9). Cognitive aspects of schizophrenia, including attention and vigilance, have been a continuing focus in the evaluation of this disease $(10,11)$. A recent study of patients with frontal lobe lesions demonstrated that these patients also had a deficiency in maintaining tasks that require sustained attention (12). Frontal lobe dysfunction

The author would like to thank Dr. Robert Cohen and Dr. Eric Koniki, of the Clinical Neurosciences Branch, N.I.H., for providing assistance with the content and style of this review. 
in schizophrenia has, therefore, been strongly suggested from several research paradigms. Recently, however, a localization of this deficit in a specific brain region has been demonstrated by functional imaging techniques.

Early functional imaging studies of cerebral metabolism utilized Xe [133] inhalation or carotid injection to examine relative blood flow rates. Ingvar and Frazen applied this technology to the study of schizophrenic patients and demonstrated a relative decrease in cerebral blood flow in these patients $(13,14)$. They reported that normal persons demonstrated a relatively higher blood flow in the prefrontal cortex than in temporal or parietal corticies. In schizophrenic patients, however, this hyperfrontality was attenuated and the patients were described as hypofrontal. A review of attempts to replicate these findings is available (15). Cerebral blood flow studies using Xe [133], however, have several limitations, including lower spatial resolution and provision of only relative blood flow values. PET scan technology has been useful in confirming, and investigating more effectively, hypofrontality in schizophrenia. Recent advances in controlling the behavioral aspects of the scanning procedure and evidence of a more precise localization of the dysfunction in the mid-prefrontal cortex may permit significant advances in the understanding of schizophrenia (16).

\section{PET TECHNOLOGY}

PET scanning utilizes short lived, radioactively labeled biomolecules to study normal and diseased states in brain tissues. A positron emitting isotope is incorporated into metabolites, or drugs, by using a cyclotron which forms an unstable nucleus. Within the nucleus of the isotope, a proton transforms into a neutron. During this transformation, a positron is emitted. The positron then collides with an electron to produce two photons of light. A geometrical image of relative photon activity is then developed. A detailed review of PET technology is available (17).

One of the most useful compounds in psychiatric research has been F[18]labeled 2 flouro-2-deoxy-D glucose (FDG). The FDG tracer method, developed by Sokoloff, Reivich and coworkers (18-20), has been used to evaluate glucose metabolism in brain tissues. According to their 2-deoxyglucose model, FDG is transported into the cell and phosphorylated in a manner similar to glucose. However, unlike glucose, phosphorylated FDG is not a substrate for metabolism. Once transported into the cell, FDG is phosphorylated and degraded slowly enough to be considered essentially trapped during the scanning measurements. FDG is phosphorylated (the rate limiting step) based on metabolic needs and is, therefore, a good indicator of cellular activity. The functional imaging offered by PET opens new dimensions in the study of brain physiology. Although conventional imaging with $\mathrm{x}$-ray technology has enabled visualization of structural changes (eg. ventricular enlargement) in schizophrenia, PET may detect biochemical changes at an earlier stage and provide more information about the pathophysiology. 
TABLE 1.

Pet Studies of Frontal Cortex Metabolism in Schizophrenic Patients Off Medication

\begin{tabular}{|c|c|c|}
\hline Study & $\mathrm{S} / \mathrm{C}$ & $\begin{array}{c}\text { Frontal } \\
\text { Metabolism } \\
\text { Differences }\end{array}$ \\
\hline Farkas, et al, $1980(21)$ & $1 /$ n.r. & decreased \\
\hline Buchsbaum, et al, 1981 (22) & $5 / 5$ & decreased \\
\hline Buchsbaum, et al, 1982 (29) & $8 / 6$ & decreased \\
\hline Sheppard, et al, 1983 (30) & $12 / 12$ & nonsignificant \\
\hline Widen, et al, 1983 (31) & $6 / 12$ & decreased \\
\hline Brodie, et al, 1984 (32) & $6 / 5$ & decreased \\
\hline Buchsbaum, et al, $1984(33,34)$ & $16 / 19$ & decreased \\
\hline Buchsbaum, et al, 1984 (35) & $4 / 19$ & decreased \\
\hline DeLisi, et al, 1985 (36) & $20 / 21$ & decreased \\
\hline Jernigan, et al, 1985 (37) & $6 / 6$ & nonsignificant \\
\hline Wolkin, et al, 1985 (38) & $10 / 8$ & nonsignificant \\
\hline Sedvall, et al, 1986 (39) & $13 / 10$ & increased \\
\hline Volkow, et al, 1986 (40) & $4 / 12$ & nonsignificant \\
\hline Cohen, et al, 1987 (16) & $16 / 27$ & decreased \\
\hline Early, et al, 1987 (41) & $10 / 20$ & nonsignificant \\
\hline Gur, et al, 1987 (42) & $12 / 12$ & nonsignificant \\
\hline Wiessel, et al, 1987 (43) & $10 / 20$ & decreased* \\
\hline Wolkin, et al, 1987 (44) & $6 / 9$ & decreased \\
\hline Wolkin, et al, 1988 (45) & $13 / 8$ & decreased \\
\hline DeLisi, et al, 1989 (46) & $21 / 9$ & nonsignificant \\
\hline Gur, et al, $1989(47)$ & $20 / 18$ & nonsignificant \\
\hline
\end{tabular}

Symbols: S/C - Schizophrenic patients/control subjects; *only study reporting decreased frontal rate, yet increased A:P ratio; n.r. - not reported.

Notes: 1) All studies used age-matched controls except Buchsbaum, 1984 (quadruplet study - ages 51); Wolkin, 1985 (mean ages s/c - 38/27). Brodie, 1984, did not report ages. All remaining studies reported mean ages of $22-38$.

2) Frontal metabolism differences include reported differences in absolute frontal rates; frontal: whole slice, frontal: whole brain or anterior:posterior ratios.

3) All studies used glucose ligands except Sheppard, 1984 (0[15] and C[15]02).

\section{DEMONSTRATION OF HYPOFRONTALITY BY PET}

A search of PET literature reporting on frontal lobe glucose metabolism in schizophrenic patients uncovered approximately thirty studies. The first PET report of hypometabolic activity in the frontal cortex of a schizophrenic patient was by Farkas, Reivich and coworkers in 1980 (21). Other early studies by Buchsbaum (22) and Widen (23) confirmed the evidence of hypofrontality. Studies using medicated schizophrenic patients have generally demonstrated hypometabolic activity in the frontal cortex (24-28). Table 1, above, however, presents a review of 21 studies using only unmedicated and never medicated patients, due to a concern of possible confounding effect by neuroleptic treatment. Review of these studies reveals some inconsistent findings. Several vari- 
ables have been considered as possible sources for the discrepancy between these findings.

The variable which has received the most discussion in the literature has been neuroleptic treatment. Some investigators have questioned the validity of reports of hypometabolic activity in the frontal cortex of schizophrenics because of neuroleptic treatment concurrent with or preceding scanning procedures $(30,41)$. These investigators suggest that hypofrontality findings may be an effect of treatment and not a manefestation of schizophrenia. This view is partly supported by findings of extended clinical and pharmacokinetic effects which persist following termination of medication $(48,49)$. Additional support for their viewpoint comes from studies of never-medicated schizophrenics $(30,31,40,41)$. These studies have consistently found no significant differences in frontal lobe metabolism in schizophrenic patients. However, these findings may be due to a biological difference between new-onset and chronic schizophrenia. A recent report by Wiessel and coworkers (43) indicated that duration of illness was directly correlated with degree of hypofrontality.

Due to the concern of possible frontal lobe changes with neuroleptic treatment, most studies have utilized patients which have been taken off medication prior to the scanning procedure (wash-out studies). Of the recent studies using nonmedicated patients (see table), most have used patients off neuroleptics for at least 13 days. Some studies have used wash-out periods of only 10 days $(44,45)$. Others have used mixed samples with some patients that received limited dosages at least forty-eight hours prior to scanning (30) or some patients off neuroleptics for at least seven days (42). One study did not specify duration off medication (22).

Support for the validity of studies reporting hypofrontality in patients unmedicated prior to and during scanning procedures can be found in the reports of PET studies comparing metabolism before and during neuroleptic treatment. These reports have generally indicated that frontal glucose metabolism is either unchanged or increased, not decreased, during neuroleptic treatment (38-40,50-53). Changes in metabolism were studied with medication intervals ranging from 1 hour to 7.4 years. Further support for the validity of studies using previously medicated patients comes from dopamine receptor occupancy studies. Using $\operatorname{Br}[76]$ labeled bromospiperone binding to corpus striatum, Camdon and coworkers (54) found that after neuroleptic withdrawal, a return to $100 \%$ unoccupied receptors occurred within 7-12 days in the majority $(6 / 8)$ of subjects tested. A final answer to this question of neuroleptic effects on frontal lobe metabolism may require a prospective study of metabolic rates before, during and following neuroleptic treatment, which demonstrates a complete return to baseline metabolism.

One variable of increasingly apparent importance, which remains less than optimally controlled in most experiments to date, is behavioral activity during PET scanning. Most studies of metabolic activity have used resting subjects. Many studies have taken measures to limit sensory stimulation of the patient 
during scanning in order to provide a more uniform sensory environment. Other studies have used somatosensory stimuli in the form of mild electrical shock to the right forearm $(33,34,36,50)$. Somatosensory stimuli have been used to maintain a uniform sensory environment between subjects and preferentially activate the frontal lobes $(55,56)$. Xe [133] blood flow studies have reported attenuation of this activation in schizophrenic subjects (57). However, a recent PET study comparing sensory environments during scanning found that somatosensory stimulation is not an effective method of frontal cortex activation (58). In a study of 52 normal volunteers, Cohen and co-workers compared the effects of somatosensory stimulation, auditory discrimination and resting states on frontal metabolic activity. Increased metabolic rates were found in the right middle prefrontal cortex during the auditory discrimination task. This increased rate demonstrated a direct correlation with the accuracy of the subjects' performance, suggesting that this area may be very important in attention maintenance. The somatosensory stimuli, however, was not associated with generalized activation of the frontal cortex.

Continuous performance tasks, such as the auditory discrimination task, have also been used to study the attention deficits in schizophrenia. Continuous performance tasks have been shown to be highly sensitive to functional illness (59) and have been used to demonstrate attention deficits in schizophrenia (60). Their attention deficit is evident in several areas. They often fail to attend to novel stimuli (61). Once attention is attained, they often fail to maintain task performance. The fronal lobe appears to be involved in anticipatory responding. The fronal lobe deficit theory of schizophrenia, therefore, is supported by the patient's poor preparation for response. A study by Cohen (16) examining 16 schizophrenic patients, performing auditory discrimination tasks during PET scanning, demonstrated specific areas of deficient metabolism. Of the 55 specific regions examined, only the left anterior, medial and right anterior areas of the frontal cortex, in a single plane, demonstrated significant metabolic deficits. An earlier study by Jernigan and co-workers (37) also used an auditory discrimination task to study schizophrenic patients. Their finding of nonsignificant changes, however, may have been due to a limited sample size (6 patients) or the limited number of slices analyzed (1 slice).

\section{CONCLUSIONS}

Greater than $50 \%$ of the PET studies investigating frontal lobe metabolism have demonstrated decreased activity in schizophrenic patients. The variability of findings in the frontal cortex do not appear to be caused by neuroleptic medication. However, a prospective study of neuroleptic effects before, during and after medication may be useful. Some authors have suggested that the failure to consistently confirm frontal deficits may be due to different pathological groups of schizophrenics (eg. frontal and temporal lesions). Others have suggested that variance between studies may reflect the chronicity of the disease. 
Additional sources of variance may include specificity of analysis (eg. whole frontal cortex slice vs. subdivided areas) and sample size. Frontal cortex activating tasks may also reduce the variability between studies by utilizing the recognized attention deficit seen in most of these patients.

In summary, an area of metabolic dysfunction in the prefrontal cortex of schizophrenic patients has been demonstrated through the use of positron emission tomography. The inconsistencies in the attempts to replicate these findings are probably due to multiple variables. The fact that $50 \%$ of the studies have succeeded in demonstrating a frontal lobe deficit is remarkable, given the lack of frontal activating tasks and limited subdivision of frontal areas in most studies.

In conclusion, PET technology is opening new dimensions to the study of psychiatric research. PET offers functional imaging not provided by previous analytical instruments and greater precision and depth than other newly developed techniques. Further refinement of nuclear and computer technology, and experimental methodology promise to make PET an invaluable tool in the study of schizophrenia and other mental diseases.

\section{BIBLIOGRAPHY}

1. Christison GW, Casanova MF, et al: A quantitative investigation of hippocampal pyramidal cell size, shape, and variability of orientation in schizophrenia. Arch Gen Psychiatry 46:1027-1032, 1989

2. Kleinman JE, Casanova MF, Jaskiw GE: The neuropathology of schizophrenia. Schizophr Bull 14:209-216, 1988

3. Bennet J, Enna J, Bylund D, et al: Neurotransmitter receptors in frontal cortex of schizophrenics. Arch Gen Psychiatry 36:927-934, 1979

4. Whitaker P, Crow T, Ferrier I: Tritiated LSD binding in frontal cortex in schizophrenia. Arch Gen Psychiatry 38:278-280, 1981

5. Toru M, Watanabe S, Nishikawa T, Noda K: Neurotransmitter receptors in postmortem schizophrenic brains. In: Yoshida H, ed. Recent Research on Neurotransmitter Receptors. Amsterdam: Exerpta Medica, 1986

6. Hanada S, Mita T, Nishino N, Tanaka C: [3H] Muscimol binding in autopsied brains of chronic schizophrenics. Life Sci 40:259-266, 1986

7. Benes F, Davidson J, Bird E: Quantitative cytoarchitectural studies of the cortex of schizophrenics. Arch Gen Psychiatry 43:31-35, 1986

8. Miyakawa T, Sumiyoshi S, Deshimaru M: Electron microscopic study in schizophrenia: Mechanism of pathological changes. Acta Neuropathol 20:67-77, 1972

9. Andreason N, Nasrallah H, Dunn Y, et al: Structural abnormalities in the frontal system in schizophrenia: A magnetic resonnance imaging study. Arch Gen Psychiatry 14:136-144, 1986

10. Mirsky A: Neuropsychological bases of schizophrenia. Annu Rev Psycho 20:321348,1969

11. Garmezy N: The psychology and psychopathology of attention. Schizophr Bull $3: 360-369,1977$ 
12. Wilkens A, Shallice T, McCarthy R: Frontal lesions and sustained attention. Neuropsychologica 25:359-365, 1987

13. Ingvar D: Abnormal distribution of cerebral activity in chronic schizophrenia: $A$ neurophysiological interpretation. In: CF Baxter and T Melnechuck (eds). Perspectives in Schizophrenia Research. River Press, New York, 1980

14. Frazen G, Ingvar D: Absence of activation in frontal structures during psychological testing of chronic schizophrenics. J Neuro Neurosurg Psychiatry 38:1027-1032, 1975

15. Weinberger D, Kleinman J: Observations on the brain. In: American Psychiatric Association Annual Review Vol. 5. Washington: APA Press, 1986

16. Cohen R, Semple W, Gross M: Dysfunction in prefrontal substrate of substained attention in schizophrenia. Life Sci 40:2031-39, 1987

17. Cohen R, Semple W, Gross M: Positron emission tomography. Psychiatr Clin North Am 9:63-79, 1986

18. Sokoloff L, Reivich M, Kennedy C: The [14 C] deoxyglucose method for the measurement of local cerebral glucose utilization: Theory procedure and normal values in the conscious and anesthetized albino rat. J Neurochem 28:897-916, 1977

19. Reivich M, Kuhl D, Wolf A: The [ $18 \mathrm{~F}$ ] flourodeoxyglucose method for the measurement of local cerebral glucose utilization in man. Cir Res 44:127-137, 1979

20. Sokoloff L: Localization of functional activity of the central nervous system by measurement of glucose utilization with radioactive deoxyglucose. J Cerebral Blood Flow Metab 1:7-36, 1981

21. Farkas T, Reivich M, Alavi A: The application of deoxy-2-fluoro-D-glucose and positron emission tomography in the study of psychiatric conditions, In: Passonneau JF, Hawkins RA, Lust WD, et al (eds): Cerebral Metabolism and Neural Function. Baltimore, Williams \& Wilkins Co. 1980

22. Buchsbaum M, Kessler R, Bunney W, et al: Simultaneous electroencephalography and cerebral glucography with positron emission tomography in normals and patients with schizophrenia. J Cerebral Blood Flow Metab 1 (suppl 1):457-458, 1981

23. Widen L, Bergstrom M, Blomquist G: Glucose metabolism in patients with schizophrenia: Emission computed tomography measurements with [11-C] glucose. J Cerebral Blood Flow Metab 1 (Suppl 1):5455-5456, 1981

24. Farkas T, Wolf A, Jaiger J: Regional brain glucose metabolism in chronic schizophrenia. A positron emission transaxial tomographic study. Arch Gen Psychiatry 41:293300,1984

25. Kling A, Metter E, Ridge W: Comparison of PET measurement of local brain glucose metabolism and CAT measurement of atrophy in chronic schizophrenia and depression. Am J Psychiatry 143:175-80, 1986

26. Volkow N, Brodie J, Wolf A: Brain organization in schizophrenia. J Cerebral Blood Flow Metab 6:441-446, 1986

27. Kishimoto H, Kuwahara H, Ohno S: Three subtypes of schizophrenia identified using [11C]-glucose positron emission tomography. Psychiatry Res 21:285-292, 1987

28. Volkow N, Wolf A, VanGelder P: Phenomonological correlates of metabolic activity in 18 patients with chronic schizophrinia. Am J Psychiatry 144:151-158, 1987

29. Buchsbaum M, Ingvar D, Kessler R, et al: Cerebral glucography with positron tomography: Use in normal subjects and in patients with schizophrenia. Arch Gen Psychiatry 39:251-259, 1982 
30. Sheppard G, Govzelier J, Manchanda R: [15, 0] positron emmission tomographic scanning in predominantly never-treated acute schizophrenic patients. Lancet 2:448452,1983

31. Widen L, Blomquist G, Greitz T: PET studies of glucose metabolism in patients with schizophrenia. AJNR 4:550-552, 1983

32. Brodie J, Christman D, Corona J, et al: Patterns of metabolic activity in the treatment of schizophrenia. Ann Neuro 15 (Suppl 51); 166-169, 1984

33. Buchsbaum M, Cappelletti J, Ball R, et al: Positron emission tomographic image measurement in schizophrenia and affective disorders. Ann Neuro 15 (Suppl 51); $157-165,1984$

34. Buchsbaum M, DeLisi L, Holcomb H, et al: Anteroposterior gradients in cerebral glucose use in schizophrenia and affective disorders. Arch Gen Psychiatry 41:1159_ 1166,1984

35. Buchsbaum M, Mirsky A, DeLisi L, et al: The Genain quadruplets: electrophysiological, positron emission, and x-ray tomographic studies. Psychiatry Res 13:95-108, 1984

36. DeLisi L, Buchsbaum M, Holcomb H: Clinical correlates of decreased anteroposterior metabolic gradients in positron emission tomography (PET) of schizophrenia patients. Am J Psychiatry 142:78-81, 1985

37. Jernigan T, Sargent T, Pfefferbaum A: [18] Fluorodeoxyglucose PET in schizophrenia. Psychiatry Res 16:317-329, 1985

38. Wolkin A, Jaeger J, Brodie J: Persistence of cerebral metabolic abnormalities in chronic schizophrenia as determined by positron emission tomography. Am J Psychiatry $142: 564-571,1985$

39. Sedvall G, Blomquist G, DePaulis T: PET studies on brain energy metabolism and dopamine receptors in schizophrenic patients and monkeys. In: Pichot P, Berner P, et al: (eds) Psychiatry: The State of the Art: Biological Psychiatry, Higher Nervous System Activity. New York, Plenum Press 1985

40. Volkow N, Brodie J, Wolf A: Brain metabolism in patients with schizophrenia before and after acute neuroleptic administration. J Neurol Neurosurg and Psychiatry 49:1199-1202, 1986

41. Early T, Reiman E, Raichle M: Left globus pallidus abnormality in never-medicated patients with schizophrenia. Proc Natl Acad Sci USA 84:561-563, 1987

42. Gur R, Resnick S, Alavi A: Regional brain function in schizophrenia I: A positron emission tomography study. Arch Gen Psychiatry 44:119-125, 1987

43. Wiessel F, Wik G, Blomquist S: Regional brain glucose metabolism in drug free schizophrenic patients and clinical correlates. Acta Psychiatr Scand 76:628-641, 1987

44. Wolkin A, Angrist B, Wolf A: Effects of amphetamine on local cerebral metabolism in normal and schizophrenic subjects as determined by positron emission tomography. Psychopharmacology 92:241-246, 1987

45. Wolkin A, Angrist B, Wolf A: Low frontal glucose utilization in chronic schizophrenia: A replication study. Am J Psychiatry 145:251-253, 1988

46. DeLisi L, Buchsbaum M, Holcomb H: Increased temprol lobe glucose use in chronic schizophrenia patients. Biol Psychiatry 25:835-851, 1989

47. Gur RE, Resnick S, and Gur RC: Laterality and frontality of cerebral blood flow and metabolism in schizophrenia; relationship to symptom specificity. Psychiatry Res $27: 325-334,1989$ 
48. Hershon H, Kennedy P, and McGuire R: Persistence of extrapyramidal disorders and psychiatric relapse after withdrawal of long term phenothiazine therapy. $\mathrm{Br} \mathrm{J}$ Psychiatry 120:41-50, 1972

49. Baldessarini R: Drugs in the treatment of psychiatric disorders. In: Goodman L and Gilman A, eds., The Pharmacological Basis of Therapeutics. New York, MacMillan, 1985

50. DeLisi L, Holcomb H, Cohen R: Positron emission tomography in schizophrenia patients with and without neuroleptic medication. J Cerebral Blood Flow Meta 5:201-206, 1985

51. Buchsbaum M, Wu J, DeLisi L, et al: Positron emission tomography studies of basal ganglia and somatosensory cortex neuroleptic drug effects: Differences between normal controls and schizophrenic patients. Biol Psychiatry 22:479-494, 1987

52. Gur RE, Resnick S, Gur RC: Regional brain function in schizophrenia II: Repeated evaluation with positron emission tomography. Arch Gen Psychiatry 44:126-129, 1987

53. Szechtman H, Nahmias C, Garnett S: Effect of neuroleptics on altered cerebral glucose metabolism in schizophrenia. Arch Gen Psychiatry 45:523-532, 1988

54. Camdon $\mathrm{H}$, Baron J, Boulenger J, et al: In vivo assay for neuroleptic receptor binding in the striatum-positron tomography in humans. Br J Psychiatry 151:824-830, 1987

55. Foit A, Larsen B, Hattori S: Cortical activation during somatosensory stimulation and voluntary movement in man: A regional cerebral blood flow study. Electroenceph$\log$ Clin Neurophysiol 50:426-436, 1980

56. Buchsbaum M, Holcomb $\mathrm{H}$, Kessler R, et al: Lateralized asymmentries in glucose uptake assessed by positron emission tomography in patients with schizophrenia and normal controls. In: Flor-Henry P \& Gruzelier J (eds), Laterality and Psychopathology. Amsterdam: Elsevier Science, 1983

57. Ingvar D: Abnormal distribution of cerebral activity in chronic schizophrenia: A neurophysiological interpretation. In: C.F. Baxter and T. Melnechuck (eds). Perspectives in Schizophrenia Research. River Press, New York, 1980

58. Cohen R, Semple W, Gross M, et al: Functional localization of substained attention: Comparison to sensory stimulation in the absence of instruction. Neuropsychiatry Neuropsychology and Behavioral Neurology 1:3-20, 1988

59. Erlenmeyer-Kimling L, Marcuse Y, Cornblatt B: The New York high risk project. In: Watt, JF, Anthony EJ, et al. (eds). Children at Risk for Schizophrenia. Cambridge University Press. Cambridge, England, 1984

60. Kornetsky C and Orzack M: Physiological and behavioral correlates of attention dysfunction in schizophrenic patients. J Psychiatr Res 14:69-79, 1978

61. Zahn TP: Studies of autonomic psychophysiology and attention in schizophrenia. Schizophr Bull 14:204-208, 1988 